\title{
Autotranplantasi Caninus Maxilla pada Soket Incisivus Lateral Maxilla menggunakan Anestesi Lokal
}

\author{
Adi Subekti Putra*, Maria Gorreti**, dan Poerwati Soetji Rahajoe ${ }^{* * *}$ \\ *Residen Bedah Mulut \& Maksilofasial, Fakultas Kedokteran Gigi, Universitas Gadjah Mada, Yogyakarta, Indonesia \\ ${ }^{* * B}$ Bagian Bedah Mulut \& Maksilofasial Rumah Sakit Umum Pemerintah Dr. Sarjito, Yogyakarta, Indonesia \\ *** Bagian Bedah Mulut \& Maksilofasial, Fakultas Kedokteran Gigi, Universitas Gadjah Mada, Yogyakarta, Indonesia \\ *JI Denta No 1 Sekip Utara Yogyakarta, Indonesia; e-mail: adi_subekti_putra@yahoo.com
}

\begin{abstract}
ABSTRAK
Autotranplantasi gigi sebagai pilihan utama mempunyai banyak keuntungan selama periode gigi bercampur karena berkontribusi untuk merangsang pertumbuhan tulang, hal ini pun tidak didapat pada implan gigi. Gigi donor terbaik untuk autotransplantasi adalah ketika perkembangan akar mencapai setengah atau sepertiga dari panjang total dengan apek terbuka lebar, dengan tingkat keberhasilan 94\%, sedangkan dengan akar komplet tingkat keberhasilannya lebih rendah $(84 \%)$ karena seringkali jaringan periodontal rusak saat pengambilan donor. Pada laporan kasus ini penulis melakukan autotransplantasi dengan menggunakan donor gigi yang mempunyai akar lengkap. Gigi embedded dimanfaatkan untuk menggantikan gigi caninus desidui yang mengalami rampan karies dengan autotransplantasi. Tujuan autotransplantasi pada kasus ini adalah menggantikan gigi caninus desidui yang rampan karies sehingga secara fungsi dan estetika menjadi lebih baik.
\end{abstract}

Maj Ked Gi Ind. Desember 2015; 1(2): 223 - 227

Kata kunci: embeded, autotransplantasi, akar komplet

\begin{abstract}
Autotransplantation of Maxillary Canines in Lateral Incisor Socket Using Local Anesthetic. Autotransplantation as the primary option that has many benefits over a period of mixed dentition for contributing to stimulating bone growth; it is not obtained on dental implants. Autotransplantation donor tooth is best when root development reaches half or one-third of the total length with open apex, with a success rate of $94 \%$. However in the complete root, the success rate is lower (84\%) due to periodontal issues which are often damaged when making the donor. In this case report, the authors performed the autotransplantation using a whole root donor tooth. Embedded teeth were used to replace deciduous canine teeth with rampant caries. The aim of this case is to replace rampant caries teeth that are not anatomically perfect.
\end{abstract}

Maj Ked Gi Ind. Desember 2015; 1(2): 223 - 227

Keywords: embedded, autotransplantion, complete root formation

\section{PENDAHULUAN}

Banyak solusi digunakan untuk mengganti gigi permanen yang hilang karena trauma, kerusakan, dan perkembangan yang tidak tepat selama periode gigi bercampur, meliputi gigi palsu sebagian permanen atau semi permanen, implan, ortodontik untuk menutup ruang dan gigi permanen autotransplantasi. Gigi palsu, implant dan perawatan ortodontik membutuhkan biaya yang mahal, membutuhkan pemeliharaan khusus, dan memiliki ketidaknyamanan karena berupa benda asing. ${ }^{1}$

Autotranplantasi gigi merupakan pilihan utama yang mempunyai banyak keuntungan selama periode gigibercampurkarenaberkontribusiuntukmerangsang pertumbuhan tulang, hal ini pun tidak didapat pada implant gigi. ${ }^{2}$ Keuntungan autotransplantasi meliputi kemungkinan mempertahankan kelangsungan hidup ligament periodontal, pergerakan ortodontik dan mengurangi pembuangan tulang alveolar dan gingival serta membentuk kontur alami. Biaya autotransplantasi lebih murah dibandingkan dengan implan karena prosedurnya dilakukan dalam sekali kunjungan dan tidak memerlukan protesa. ${ }^{3}$

Autotranplantasi gigi adalah teknik bedah yang memindahkan gigi dari satu soket ke soket yang lain untuk menggantikan gigi yang hilang atau indikasi tertentu pada satu individu. ${ }^{4}$ Indikasi autotranplantasi adalah tidak ada lesi periapikal dan periodontitis pada resipien, gigi yang diganti berindikasi dicabut, gigi donor harus sudah ada akar minimal $3 \mathrm{~mm}$, gigi donor sudah ada bifurkasio, 
gigi donor besarnya sama atau sedikit lebih kecil daripada gigi yang diganti, keadaan umum pasien baik, kebersihan mulut baik. ${ }^{5}$

Kontra indikasi autotransplantasi adalah gigi yang sangat goyang, tulang alveolus sudah tidak ada, gigi yang sakit dicabut/dicabut utuh. Kriteria keberhasilan autotransplantasi adalah gigi melekat relatif kuat, tidak ada rasa sakit, gingiva sekitar normal, tidak ada resorbsi tulang, tidak ada poket periodontal, tidak ada fistel, tidak ada resorbsi akar gigi, tidak ada lesi periapikal, ada membran periodontalis, ada pertumbuhan akar. ${ }^{6}$

Gigi donor terbaik untuk autotransplantasi adalah ketika perkembangan akar mencapai setengah atau sepertiga dari panjang total dengan apek terbuka lebar. ${ }^{5}$ Pada laporan kasus ini penulis melakukan autotransplantasi dengan menggunakan donor gigi yang mempunyai akar lengkap. Lundberg dan Isaksson melaporkan tingkat keberhasilan donor gigi dengan akar belum sempurna adalah $94 \%$ dan donor gigi dengan akar lengkap adalah $84 \%$, karena seringkali jaringan periodontal rusak saat pengambilan donor. ${ }^{7}$ Sedangkan Majare melaporkan keberhasilan yang tinggi pada donor gigi akar lengkap. ${ }^{8}$

Pada kasus ini gigi embeded yang selama ini dibuang, dimanfaatkan untuk mengganti (autotranplantasi) gigi caninus desidui yang rampan karies. Autotranplantasi dipilih karena berkontribusi untuk merangsang pertumbuhan tulang pada periode gigi bercampur, hal ini pun tidak didapat pada implan gigi.

\section{STUDI KASUS}

Seorang pasien (16) rujukan RSU Gunung Kidul, datang ke Poli Bedah Mulut RSUP. Dr. Sardjito, Yogyakarta untuk mencabutkan gigi depan kanan atas yang gingsul dan sering melukai bibir saat mengunyah. Pasien tidak memiliki riwayat penyakit sistemik dan alergi obat-obatan.

Pada pemeriksaan klinis didapatkan keadaan umum pasien baik dan kooperatif. Pemeriksaan ekstra oral wajah simetris dalam batas normal. Pemeriksaan intra oral, gigi incisivus sentral satu kanan maksila rotasi (11), gigi incisivus sentral dua kanan maksila labioversi (12) dan gigi caninus desidui (53) radices. Pada pemeriksaan rontgen orthopantomogram (OPG) terlihat adanya gigi caninus yang embedded (13). Pada kunjungan ini dilakukan pemeriksaan darah lengkap. Keluarga pasien dijelaskan soal rencana pengambilan gigi impaksi yang terpendam dan pemasangan kembali untuk menggantikan gigi caninus desidui.

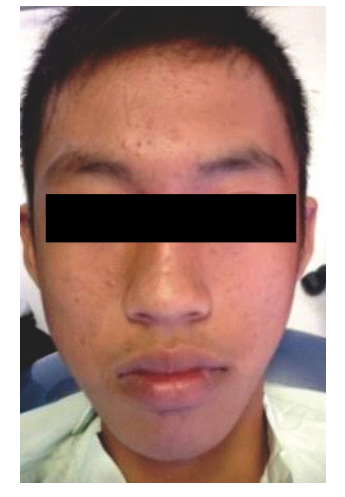

(A) Foto ekstra oral pasien

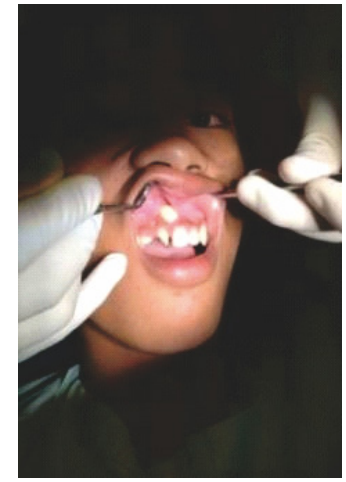

(B) Foto intra oral pasien

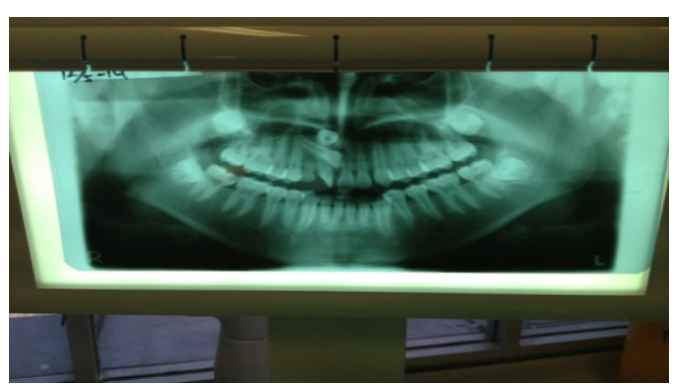

(C) Rontgen orthopanthomogram menunjukkan gigi caninus maksila kanan (13) yang embedded

Pada kunjungan berikutnya, pasien dilakukan odontektomi gigi 13, ekstraksi 12 dan caninus desidui serta autotransplantasi gigi 13 menggantikan gigi desidui. Sebelum tindakan keluarga dan pasien kembali dijelaskan rencana tindakan dan mengisi persetujuan tindakan medis. Operasi pada kasus ini menggunakan anestesi lokal dengan flap triangular. Operasi dimulai dengan odontektomi gigi 13 dan direndam dalam larutan $\mathrm{NaCl}$, kemudian dilanjutkan ekstraksi gigi 12 dan caninus desidui. Setelah selesai gigi 13 diadaptasi disoket caninus desidui dengan penyesuaian ukuran lebar soket gigi, serta gigi 11 di rotasi ke arah normal. Fiksasi dengan essig untuk stabilisai gigi 13 dan 11 dengan posisi infra oklusi yang diikuti pembentukan gigi 13 menyerupai gigi 12 , kemudian dilakukan suturing interrupted dengan safil 3.0. 


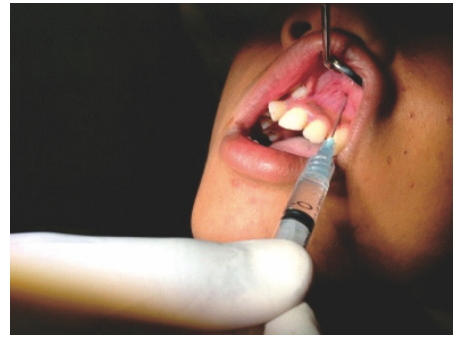

(D) Anestesi lokal

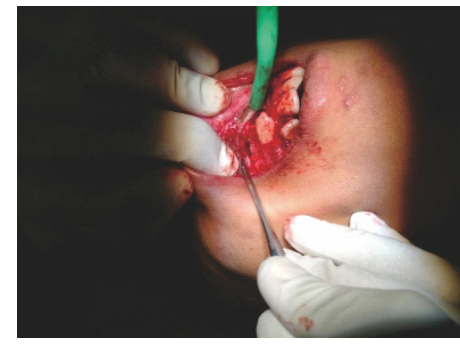

(E) Pembuatan flap triangular

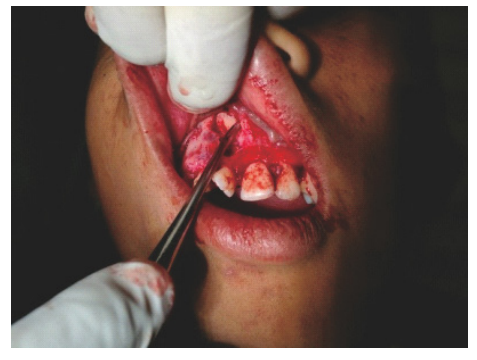

(F) Odontektomi gigi 13

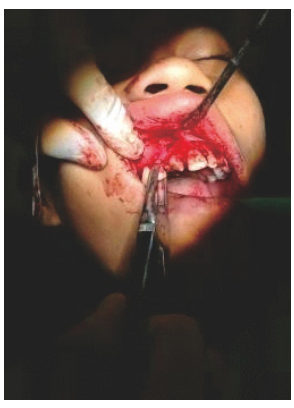

(G) Pengepasan ukuran soket gig

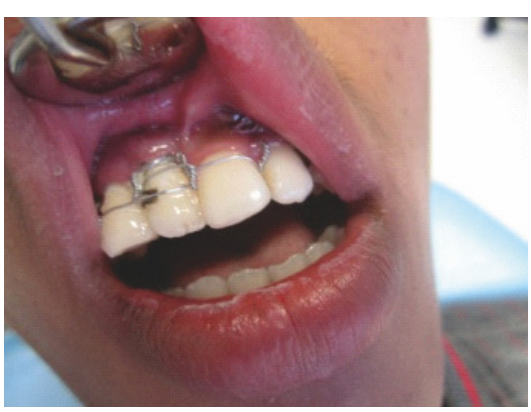

(I) Kontrol $\mathrm{H}+7$

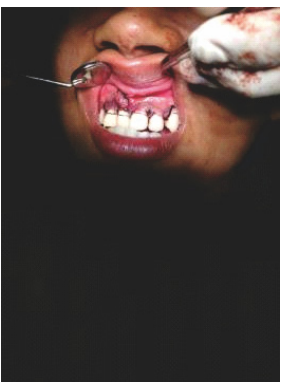

(H) Post fiksasi dan transplantasi 13

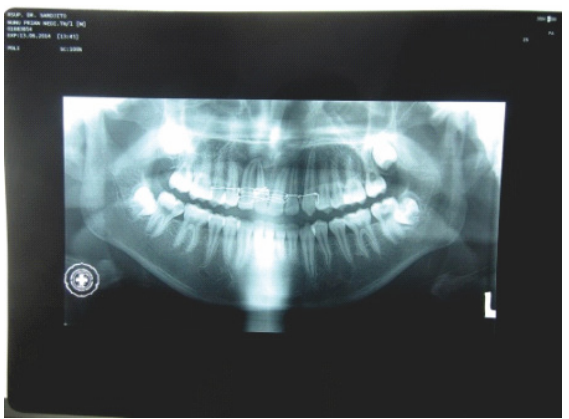

(J) Rontgen OPG H+30

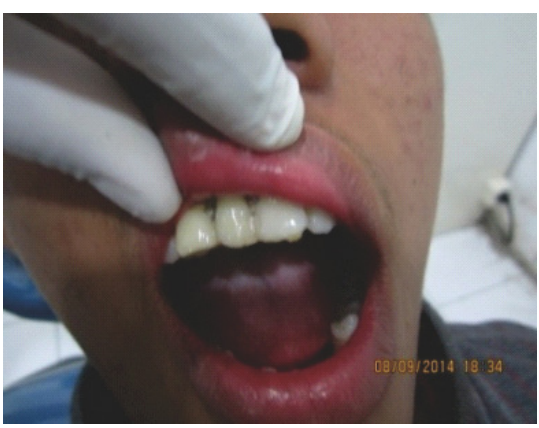

(K) Kontrol 3 bulan post op

Medikasi post operasi diberikan resep berupa Amoxicilin $500 \mathrm{mg}$, Metilprednisolon $4 \mathrm{mg}$, Asam Mefenamat $500 \mathrm{mg}$ dan Osofan $400 \mathrm{mg} \mathrm{2 \times 1}$. Pasien disarankan untuk menjaga kebersihan mulut dan luka operasi serta lepas jahitan 1 minggu kemudian.
Seminggu setelah operasi pasien kontrol, perdarahan dan keluhan yang berarti tidak dijumpai. Pembengkakan atau parestesi tidak terjadi. Pada kunjungan ini dilakukan pengambilan benang. Pada kontrol 3 bulan setelah operasi tidak ditemukan kegoyahan, resesi, fistel dan perubahan warna pada gigi. 


\section{PEMBAHASAN}

Rehabilitasi gigi setelah kehilangan satu atau lebih gigi dapat dicapai dengan beberapa teknik, termasuk protesa lepasan atau tetap, implan, atau autotransplantasi. ${ }^{1}$ Autotranplantasi gigi adalah teknik bedah yang memindahkan gigi dari satu soket ke soket yang lain untuk menggantikan gigi yang hilang atau indikasi tertentu pada satu individu. ${ }^{4}$ Keuntungan autotransplantasi meliputi kemungkinan mempertahankan kelangsungan hidup ligamen periodontal, pergerakan ortodontik dan mengurangi pembuangan tulang alveolar dan gingiva serta membentuk kontur alami. Biaya autotransplantasi lebih murah dibandingkan dengan implan gigi karena prosedur dilakukan dalam satu kunjungan dan tidak memerlukan protesa. ${ }^{3}$

Autotransplantasi juga memiliki beberapa kelemahan, termasuk fakta bahwa secara teknis membutuhkan bedah sehingga trauma bedah dapat menyebabkan kerusakan ireversibel pada ligamen periodontal, gigi donor yang kompatibel, harus tersedia soket penerima, tingkat keberhasilan jangka panjang autotransplantasi mungkin tidak sama dengan implan gigi osseointegrasi. Diperlukan terapi endodontik dalam kasus-kasus gigi donor dengan akar berkembang penuh. Dapat terjadi komplikasi seperti ankilosis, inflamasi, resorpsi akar dan gigi karies. ${ }^{9}$

Kunci keberhasilan prosedur ini adalah mempertahankan kelangsungan hidup ligamen periodontal gigi transplantasi, karena sel-sel ligamen periodontal sangat sensitif terhadap perubahan osmotik dan kelangsungan hidup mereka dapat berkurang jika kondisi ektraoral saat tindakan cukup kering dalam waktu yang lama. ${ }^{10}$

Pada kasus ini pasien datang untuk mencabutkan gigi seri kanan atas yang gingsul dan sering menggigit bibir saat makan. Pada rontgen didapatkan gigi caninus maksila kanan atas yang embeded. Dari penemuan tersebut direncanakan odontektomi 13, ekstraksi 12 dan caninus desidui serta autotranplantasi 13 menggantikan gigi 12 . Pada beberapa kasus gigi embeded sering kali dibuang, namun pada kasus ini dimanfaatkan untuk menggantikan gigi caninus desidui.
Autotransplantasi dipilih pada kasus ini mengingat teknik ini efektif untuk merehabilitasi gigi di usia pertumbuhan karena berkontribusi untuk merangsang pertumbuhan tulang, dan merupakan kontra indikasi implant gigi.

Pada kasus ini fiksasi autotransplantasi 13 menggunakan metode Essig karena dianggap lebih stabil dan terjangkau dari jaminan pengobatan pasien. Pada kasus ini tidak dilakukan pemasangan graft karena pengurangan tulang yang minimal saat odontektomi dan diberikan medikasi Osofan untuk merangsang pertumbuhan tulang.

\section{KESIMPULAN}

Autotransplantasi dipilih pada kasus ini mengingat teknik ini efektif untuk merehabilitasi gigi di usia pertumbuhan karena berkontribusi untuk merangsang pertumbuhan tulang, dan merupakan kontra indikasi implant gigi. Autotransplantasi merupakan prosedur yang terbaik untuk periode gigi bercampur dengan morbiditas yang rendah. Dengan indikasi yang benar dan teknik bedah yang tepat dapat memberi hasil yang sangat baik seperti pada laporan kasus ini.

\section{DAFTAR PUSTAKA}

1. Czochrowska EM, Stenvik A, Bjercke B, Zachrisson BU. Outcome of tooth transplantation: Survival and successrates 17-41 years post-treatment. Am J Orthod DentofacialOrthop. 2008; 121: 110-9.

2. Zachrisson BU, Stenvik A, Haanaes HR. Management of missing maxillary anterior teeth with emphasis on autotransplantation. Am J Orthod Dentofacial Orthop. 2004; 126: 284-8.

3. Baviz JB. Autotransplantation of teeth: a procedure that gets no respect. Oral Surg Oral Med Oral Pathol Oral Radiol Endod. 2010; 110: 441.

4. Leffingwell CM. Autogenous tooth transplantation: a therapeutic alternative. Dent Surv. 2013; 56(2): 22-3, 26. 
5. Andreasen JO, Andersson L, Tsukiboshi M. Autotransplantation of teeth to anterior region. In: Andreasen JO, Andersson L, Andreasen FM. Textbook and color atlas of traumatics injuries to the teeth. Denmark: Wiley-Blackwell. 2007; H. 740-59.

6. Sato $F$, Lamashita $H$, Vidote R, Moraes M, Mazzonetto RO. O transplante dentário autógenocomo alternativa à reabilitação nas perdasunitárias. Rev Bras Cirur Traumato Buco-Maxilo Facial. 2007; 1(1): 52-7.

7. Lundberg $T$, Isaksson S. A clinical follow up study of 278 autotransplanted teeth. Br J Oral Maxillofac Surg. 2007; 34: 181-5.

8. Mejare B, Wannfors K, Jansson L. A prospective study on transplantation of third molars with complete root formation. Oral Surg Oral Med Oral Pathol Oral Radiol Endod. 2004; 97: 231-8.
9. Teixeira CS, Pasternak Jr. B, Vansan LP, Sousa-Neto MD. Autogenous transplantation of teeth with complete root formation: two case reports. Int Endod J. 2006; 39: 977-985.

10. Bae JH, Choi YH, Cho BH, Kim YK, Kim SG. Autotransplantation of teeth with complete root formation: a case series. J Endod 2010; 36: $1422-1426$.

11. Gassner, Bosch R, Tarkan T, Rudger E. Prevalence of dental trauma in 600 patients with facial injuries: Implication for prevention. Oral Surg Oral Med Oral Pathol Oral Radiol Endod. 2007; 87: 27-33.

12. Miloro M. Peterson's of oral and maxillofacial surgery. 2nd ed. Hamilton, London: BC Decker Inc. 2004; H. 140-153. 